\title{
Absorption of different lead compounds
}

\author{
D. BARLTROP \\ M.D., F.R.C.P.
}

\author{
F. MEEK \\ A.A.I.M.T., A.R.M.I.T.
}

Paediatric Unit, St Mary's Hospital Medical School, London

\section{Summary}

A rapid method for the determination of relative absorption of dietary lead by rats is described. The influence of age, weight and dose rate has been determined and using standard conditions the tissue lead content of blood, kidney and femur are significantly correlated with each other and are a function of ingested lead. Eight lead compounds were evaluated using this technique and the findings related to lead acetate as a reference compound. Of the inorganic preparations studied, lead carbonate (basic) and metallic lead showed a twelve-fold difference in absorption, with the remaining compounds giving intermediate values. The absorption of lead from four organic compounds was determined from diets containing $7.5 \%$ corn oil added to the standard diet. Lead tallate was absorbed to the same degree as lead acetate, but lesser absorptions resulted from lead octoate, naphthenate and alsynate. The addition of corn oil to a final concentration of $7.5 \%$ of the diet enhanced the absorption of lead acetate.

\section{Introduction}

In the majority of lead poisoning cases, lead enters the body orally. This contaminating lead exists in the environment in many different chemical forms, lead sulphide or lead chloride in the mining industry, lead oxide in soil adjacent to smelters, lead carbonate, lead chromate and other lead salts used as pigments in older paints. Today the paint industry uses lead octoate, naphthenate and tallate as driers, and in the home cooking utensils and badly glazed pottery can cause lead contamination of food. It has been thought that not all forms of lead are absorbed at the same rate, but information available on relative toxicities is conflicting and poorly documented (Fairhall and Sayers, 1940; Allcroft, 1950; Kaurhausen, 1972). Some evidence from the mining industry suggests that galena (lead sulphide) represents a minimal hazard to adults, whereas lead chloride is relatively toxic. The absorption of lead from soils by plants has been related to the solubility in water of the lead compounds concerned (Maclean, Halstead and Finn, 1969) and it has been suggested that compounds which are soluble or able to be converted to soluble compounds in the gut are most readily absorbed $\bar{\omega}$ (Kaurhausen, 1972). Increasing attention to the possibility of differential toxicity has been given in connection with paints and surface coating materials, although one limited study has suggested that lead $\sigma$ additives to polymers are poorly absorbed (Gage and Litchfield, 1968). In order to investigate the relative absorptions of a wide range of organic and inorganic lead compounds, a rapid and reliable screening method was devised. Preliminary studies were undertaken to validate the selected methodology and to select standard conditions for dose rate, animal age and body weight. It has been demonstrated that lead absorption in the rat decreased from $90 \%$ to $16 \%$ of the ingested dose between the twentieth an $\mathbb{\perp}$ thirty-second day of life (Forbes and Reina, 1972 This work, however, used a carrier-free lead isotope ov and the results might not apply where large doses oral lead are involved. This paper reports the findings from preliminary studies and the initial results for a series of lead compounds.

\section{Methods and materials}

The rat was selected as the experimental animal as the absorption of lead in this species has been studied extensively in this department and by other workers. For each lead compound, eight male Wistar rats of $90-110 \mathrm{~g}$ body weight, and aged 30-32 days were used. Two animals were killed on the first day of the trial to confirm that they had not previously been exposed to lead. The remainder were used as test animals and housed in individual stainless steel and polythene cages. Lead acetate was chosen as a standard reference compound of known high lead absorption and was administered at inter- $\frac{D}{0}$ vals throughout the trials to test the reproducibility of the method. Some of the organic lead compounds $N$ used in the paint industry are oily viscous liquids and $\mathrm{N}$ required solution in corn oil before incorporation into the diet. For these compounds lead acetate in $\omega$ corn oil was used as a reference standard. Controls were also run at intervals during the trials in which $\stackrel{\circ}{ᄃ}$

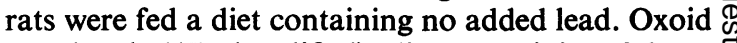
powdered 41B (modified) diet containing $2.0 \mu \mathrm{g}$ lead/g was prepared to contain $0.075 \%$ lead as the 
appropriate compound, $5 \%$ molasses and then baked to form a firm stick diet. This diet was analysed for lead and found to be homogeneous. Six test animals were supplied with a weighed portion (33-35 g) of lead-containing diet, any remaining after $48 \mathrm{hr}$ was re-weighed and the amount of lead ingested calculated by difference. Tap water containing less than $10 \mu \mathrm{g} / \mathrm{l}$ was provided ad libitum. The animals were re-weighed, killed by ether anaesthesia and dissected immediately. Approximately $2 \mathrm{ml}$ of blood were taken from the vena cava with a disposable syringe and needle, and collected into lead-free heparinized tubes. Kidneys and the right femur were removed. Blood and kidney specimens were wet ashed and taken to dryness using a sulphuric acid, nitric acid and perchloric acid digestion mixture on a sandbath at $350^{\circ} \mathrm{C}$. The femurs were dry ashed in a muffle furnace for successive periods of $20 \mathrm{hr}$ at $450^{\circ} \mathrm{C}$ and $600^{\circ} \mathrm{C}$. The ash was weighed and dissolved in $0.5 \mathrm{ml}$ of concentration hydrochloric acid (Foodstuffs Analysis Grade) and diluted to $10 \mathrm{ml}$ with distilled deionized water. An aliquot was evaporated to dryness at $85-90^{\circ} \mathrm{C}$. In each case the residues were dissolved in acid ammonium citrate buffer and analysed by an automated dithizone method (Browett and Moss, 1965). Standard statistical techniques were used in interpreting the data, namely Student's $t$-test and the Mann-Whitney non-parametric test for the significance of differences between the lead content of given tissues, and correlation coefficients for the relation between lead contents of different tissues.

\section{Findings \\ Dose studies}

The selection of the lead content for the diets was based on experiments designed to establish a dose response curve. Forty-two 32-day-old male Wistar rats weighing 90-110 $\mathrm{g}$ were allocated at random into seven equal groups, and fed varying doses of lead acetate in the range $0.04-1.0 \%$ lead for $48 \mathrm{hr}$. Tissue lead concentrations increased with dose and the response for kidney lead concentrations is shown graphically in Fig. 1. Blood, kidney and femur lead contents were all found to be well correlated (Table 1 and Fig. 2). In a further study lead naphthenate dissolved in corn oil was used and data were obtained of a diet lead content up to $0.2 \%$, above which the rats found the diet to be unpalatable. Much greater tissue concentrations were observed with lead naphthenate than with lead acetate but the curves were of a similar form with an initial rapid increase falling off slightly after a dose of $0.01 \%$ lead in the diet. The value $0.075 \%$ lead was selected for the trials since it lay on the most sensitive sections of the dose response curves and was great enough to produce significant tissue lead concentrations after $48 \mathrm{hr}$.

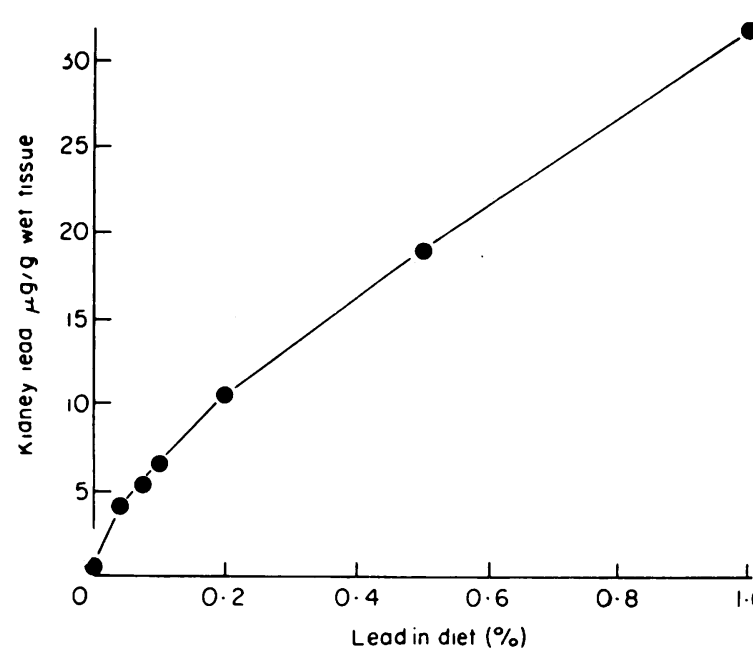

Fig. 1. Mean kidney lead concentrations for groups of six animals after $48 \mathrm{hr}$ on diets of varying added lead content.

TABLE 1. Correlation between tissue lead contents

\begin{tabular}{lccc}
\hline Tissues & r & d.f. & $P$ \\
\hline Blood v. kidney & 0.92 & 40 & $<0.001$ \\
Blood v. femur & 0.94 & 40 & $<0.001$ \\
Kidney v. femur & 0.97 & 40 & $<0.001$ \\
\hline
\end{tabular}

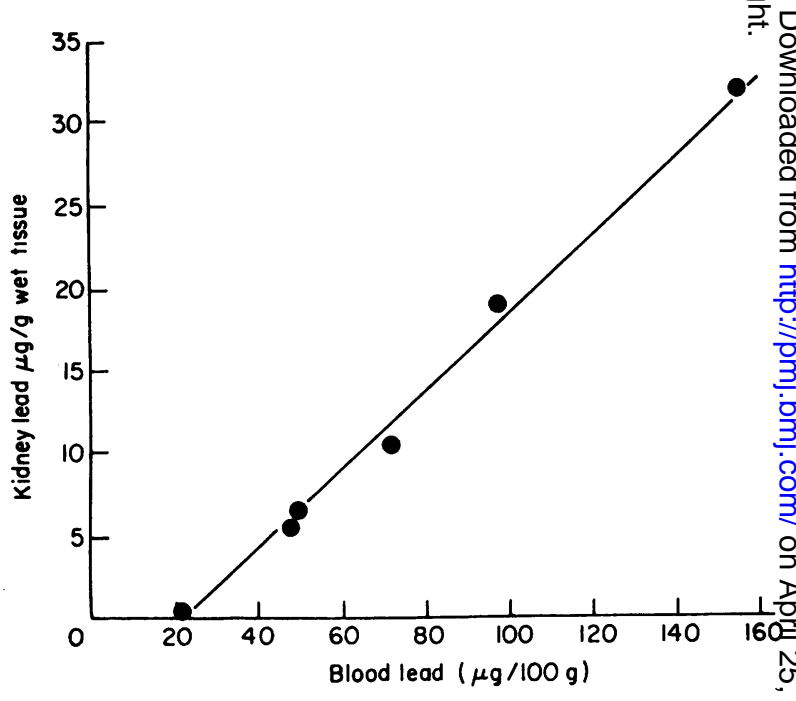

FIG. 2. Correlation between blood and kidney lead concentrations showing regression line and mean values $(r=0.92 ;$ d.f. $=40 ; P<0.001)$.

Although greater tissue lead concentrations could have been attained with greater doses, the value was kept as low as possible, bearing in mind the small doses involved in childhood toxicity. 


\section{Age study}

Following the report of large changes in lead absorption in young rats (Forbes and Reina, 1972), an experiment was designed to investigate the effect of age on lead absorption in rats under our experimental conditions. Forty-two rats were allocated at random into seven groups and fed with a control diet. At intervals during the age range 21-42 days, the control diet was withdrawn from successive groups and a diet containing $0.075 \%$ lead as lead acetate substituted for $\mathbf{4 8} \mathrm{hr}$. Kidney lead concentration, as a function of the ingested dose, decreased from $10.82 \% \times 10^{-2} \%$ to $2 \cdot 70 \times 10^{-2} \%$ between 21 and 42 days of life (Fig. 3). Although this effect was small, rats aged 30-32 days were selected for the lead compound trials to ensure minimum variation from this source.

A further study was made to investigate any influence that body weight might exert on lead absorption at a given age. Although the findings

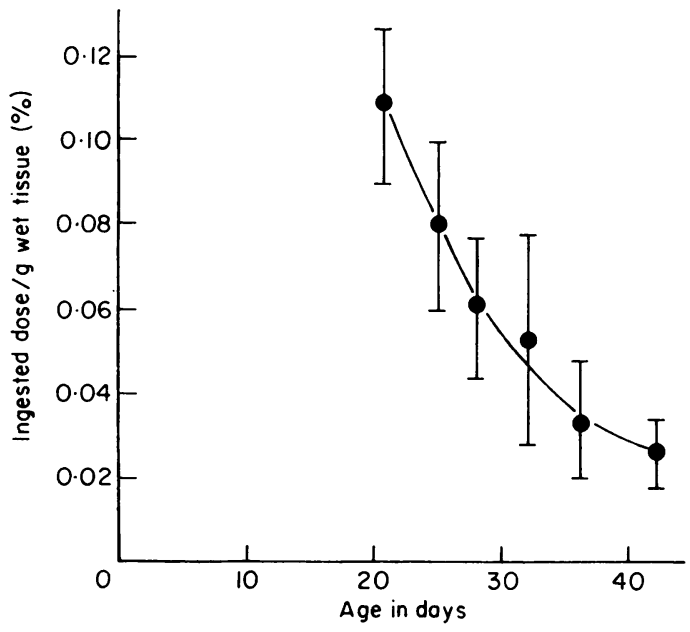

FIG. 3. Percentage ingested dose of lead per gram of wet weight kidney as a function of age for groups of six animals. were considered inconclusive, to ensure minimum $\frac{3}{\infty}$ variation, animals of body weight $90-110 \mathrm{~g}$ were $\stackrel{\varrho}{\llcorner}$ selected.

\section{Compound studies}

In addition to controls and the reference com-음 pound, lead acetate, twelve lead compounds were $\frac{\rho}{\square}$ tested (Table 2). For each compound, blood, kidneys $\varrho$ and right femurs were analysed for lead. Lead ${ }_{\omega}^{Ð}$ acetate without added corn oil gave a mean kidney lead content of $11.4 \mu \mathrm{g} / \mathrm{kidney}$. Of all the other solid. compounds, only basic lead carbonate had a greater $\vec{\omega}$ kidney lead content than the standard reference compound. Metallic lead was considerably less, lead sulphide and lead chromate were intermediate 3 . but still significantly different from lead acetate, $\rightarrow$ $P<0.001$ (Fig. 4). Lead acetate with $7.5 \%$ corn oilos in the diet resulted in a kidney lead content of $20 \mu \mathrm{g} / \stackrel{-}{.}$ kidney. Lead tallate was not significantly differento from this reference whereas lead octoate and lead ${ }^{\circ}$ naphthenate were significantly less, $P<0.02$ and $\mathrm{O}$ $P<0.01$ respectively (Fig. 5). The kidney lead contents were calculated as percentages of the relevanto lead acetate values (Table 3 ). Every compound ${ }_{\Phi}$ tested was shown to differ significantly from the controls $(P<0.001)$.

\section{Discussion}

The technique described was found to be a rapid and reliable method for the evaluation of leado absorption from different lead compounds in the environment. Although animal age and weight variables were rigidly controlled in order to minimize variation from these sources, it is likely that they had a relatively small effect. Distinction must beo made between the findings reported by other workers (Forbes and Reina, 1972; Kostial, Simonović and Pisonić, 1971) using carrier-free isotopes of lead, and the present work in which an appreciable concentration of stable lead was used. Although the dosages employed were relatively great compared with those likely to be encountered in childhood leadi

TABLE 2. Lead additives to animal diets

\begin{tabular}{|c|c|c|}
\hline $\begin{array}{l}\text { Lead (metallic) } \\
\text { Lead oxide } \\
\text { Lead sulphide } \\
\text { Lead chromate } \\
\text { Lead molybdate } \\
\text { Lead carbonate (basic) } \\
\text { Lead chloride } \\
\text { Lead stearate } \\
\text { Lead octoate } \\
\text { Lead tallate } \\
\text { Lead alsynate } \\
\text { Lead naphthenate }\end{array}$ & $\begin{array}{l}\mathrm{Pb} \\
\mathrm{PbO} \\
\mathrm{PbS} \\
\mathrm{PbCrO} \\
\mathrm{PbMoO}_{4} \\
2 \mathrm{PbCO}_{3}, \mathrm{~Pb}(\mathrm{OH})_{2} \\
\mathrm{PbCl}_{2} \\
\mathrm{~Pb}\left(\mathrm{C}_{18} \mathrm{H}_{35} \mathrm{O}_{2}\right)_{2} \\
\mathrm{~Pb}\left(\mathrm{C}_{8} \mathrm{H}_{15} \mathrm{O}_{2}\right)_{2} \\
24 \% \text { lead } \\
24 \% \text { lead } \\
24 \% \text { lead }\end{array}$ & Oily viscous liquids. \\
\hline
\end{tabular}




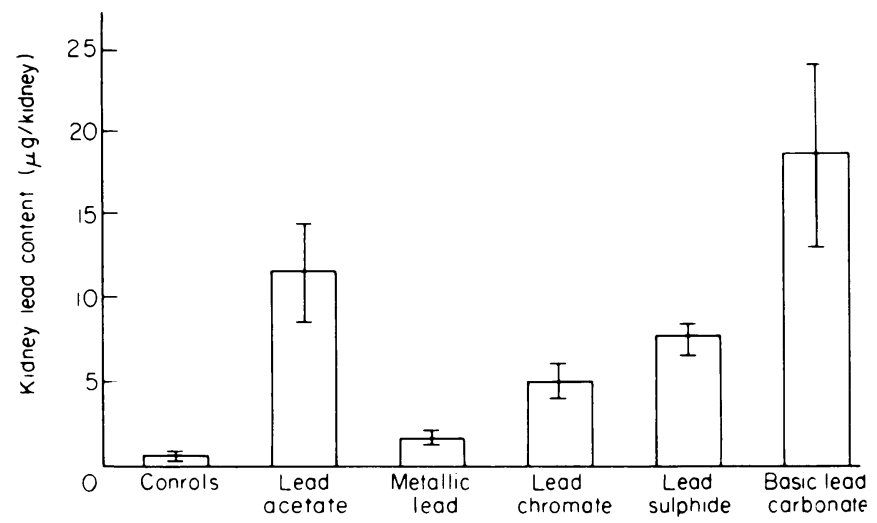

FIG. 4. Histogram showing the relative kidney lead contents for inorganic lead compounds. \pm 2 s.d.

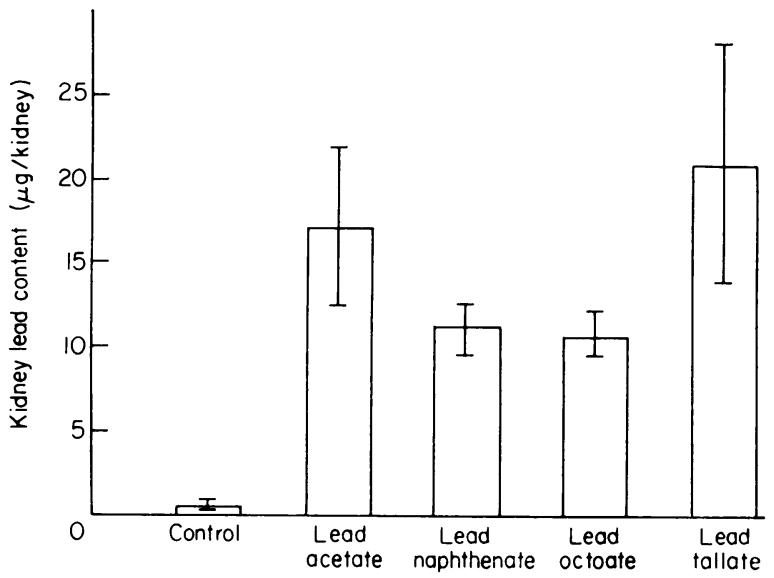

FIG. 5. Histogram showing the kidney lead content for controls, lead acetate and three organic lead compounds, incorporated into the diet with $7 \cdot 5 \%$ corn oil. \pm 2 s.d.

TABLE 3. Absorption of lead additives relative to lead acetate

\begin{tabular}{lc}
\hline Lead compound & $\begin{array}{c}\text { Percent } \\
\text { absorption }\end{array}$ \\
\hline Control (no lead) & 4 \\
Metallic lead & \\
$\quad$ (particle size 180-250 & ) \\
Lead chromate & 14 \\
Lead octoate & 44 \\
Lead naphthenate & 62 \\
Lead sulphide & 64 \\
Lead tallate & 67 \\
Lead carbonate (basic) & 121 \\
\hline
\end{tabular}

poisoning, it is nevertheless argued that the findings are more realistic than those derived from carrierfree studies. Work in this department using identical doses of stable lead labelled with ${ }^{203} \mathrm{~Pb}$ has shown that the rat absorbs only $1 \%$ of the ingested dose compared with $53 \%$ absorption that has been reported for children (Barltrop and Khoo, 1974; Alexander, Delves and Clayton, 1972). The tissue data derived from rats given lead compounds were well correlated, notably between the values obtained for blood, kidney, and bone lead content. This finding was unexpected and perhaps reflects the short-term nature of these studies.

There were significant differences in the leadec absorbed from different lead compounds, as much $\rightleftharpoons$ as a twelve-fold difference being seen between metallic lead and basic lead carbonate. The high absorption from basic lead carbonate may reflect the greater solubility of this compound in gastric juice, but it is not possible to relate the observed differences in the other compounds to their solubility in biological fluids. Although recent legislation in the U.K. concerning pencils and graphic materials is based on the content of 'soluble lead' (the amount dissolved in hydrochloric acid under standard conditions), it is doubtful whether this reflects the situation concerning the lower part of the gut from which absorption occurs.

An important finding, substantiating other work in this department (Barltrop and Khoo, 1974), was that an increase in dietary fat increased the lead absorbed from a given lead compound. With lead acetate, the mean kidney lead content was raised from $11.4 \mu \mathrm{g}$ to $20 \mu \mathrm{g}$ with the addition of $7.5 \%$ corn oil to that diet.

These data suggest that it is not possible to devise a single relevant standard for the lead content of surface-coating materials and the various environmental situations in which lead contamination occurs. Reference should be made to the chemical form of the lead involved and perhaps to dietary factors relating to each situation. 


\section{Acknowledgments}

The project upon which this publication is based was performed pursuant to Contract No. HSM 99-73-28, the Center for Disease Control, Department of Health, Education and Welfare, United States of America.

Samples of lead compounds were kindly supplied by Associated Lead Manufacturers Ltd, Lankro Chemicals Ltd, Mooney Chemicals Ltd and Nuodex Ltd.

\section{References}

Alexander, F.W., Delves, H.T. \& Clayton, B.E. (1972) The uptake and excretion by children of lead and other contaminants. Proceedings. International Symposium on Environmental Health Aspects of Lead, Amsterdam, p. 319.

Allcroft, R. (1950) Lead as a nutritional hazard to farm animals. Journal of Comparative Pathology and Therapeutics, 60, 190.

Barltrop, D. \& Khoo, H.E. (1975) The influence of nutritional factors on lead absorption. Postgraduate Medical Journal, 51, 795.
Browett, B.V. \& Moss, R. (1965) Manual and semiautomated methods for the determination of the lead content of urine. Analyst. London, 90, 715.

FaIRHALl, L.T. \& SAYERS, R.R. (1940) The relative toxicity of lead and some of its common compounds. Public Health Bulletin (U.S.) No. 253.

Forbes, G.B. \& ReINA, J.C. (1972) Effects of age on gastrointestinal absorption. Journal of Nutrition, 102, 647.

GAGE, J.C. \& Litchfield, M.H. (1968) The migration of lead polymers in the rat gastrointestinal tract. Food and Cosmetics Toxicology, 6, 329.

KAURHAUSEN, L.R. (1972) Intestinal lead absorption. International Symposium on Environmental Health Aspects of Lead, Amsterdam, p. 427.

Kostial, K., Simonović, I. \& Pisonić, M. (1971) Lead absorption from the intestine of newborn rats. Nature. London, 233, 564.

Maclean, A.J., Halstead, R.L. \& FinN, B.J. (1969) Extractability of added lead in soils and its concentration in plants. Canadian Journal of Soil Science, 49, 327. 